\title{
An Assessment of Airport Environmental Noise Action Plans with Some Financial Aspects: The Case of Athens International "Eleftherios Venizelos"
}

\author{
Konstantinos Vogiatzis \\ University of Thessaly, Department of Civil Engineering, Pedion Areos, 38334 Volos, Greece
}

(Received 8 November 2011; Accepted 13 August 2012.)

Environmental noise is an important environmental factor responsible for the degradation of the urban environment and the quality of life especially in countries where climatic conditions allow for outdoor activities and night life. Athens International Airport (AIA), "Eleftherios Venizelos," is one of the most modern, most functional, and safest airports in the world and constitutes the largest hub of air travel in southeastern Europe, encouraging strong financial and social development in the Athens greater area. AIA in collaboration with the University of Thessaly executed a complete study of aircraft noise according to the European Directive 49/2002 (ED 2002/49, 2002) under the auspices of the Ministry of Environment, Energy and Climate Change, and the Hellenic Civil Aviation Authority. In this article, an analytical evaluation and an in-depth assessment of environmental noise action plans aiming, among other aspects, for the sound insulation of buildings where noise annoyance is an issue, are presented, based on 2006 and 2011 Strategic Noise Maps for both EU noise indicators $L_{\mathrm{den}}$ and $L_{\text {night }}$. Furthermore, a statistical analysis of predicted versus measured noise levels based on the existing AIA Noise Monitoring System, is also assessed.

\section{INTRODUCTION}

Environmental noise annoyance, especially from transportation, is widely accepted as an end point of environmental noise that can be taken as a basis for evaluating the impact of noise on the exposed population. People annoyed by noise may experience a variety of negative responses, such as anger, disappointment, dissatisfaction, withdrawal, helplessness, depression, anxiety, distraction, agitation, or exhaustion. ${ }^{1}$ Extensive urbanization and the increase of air transportation are the main driving forces for the airport environmental noise exposure of the population, with possible negative health effects and annoyance to the surrounding inhabitants. "Eleftherios Venizelos," Athens International Airport (AIA) is located 15 miles $(26 \mathrm{~km})$ to the east of the city of Athens and was opened in 2001 with future expansion in mind. AIA is the first Greek airport with Environmental Department certification according to EN ISO 14001 (Dec. 2000). Its two parallel runways are spaced wide enough apart to enable simultaneous operations, with its sole terminal (plus satellite) having sufficient capacity to handle a large amount of passenger traffic. AIA's two parallel runways, with a distance between their axis of $1575 \mathrm{~m}$ and a paved surface of $800 \mathrm{~m}$ of asphalt, are depicted in Table 1.

Plans have already been put in place to have up to six terminal units to cope with increased flow in the future. ${ }^{2}$ The $1614639 \mathrm{ft}^{2}\left(150000 \mathrm{~m}^{2}\right)$ terminal has 157 check-in desks and 14 air bridges, with the satellite having 10 more bridges (see Fig. (1)). In addition, there are 65 remote aircraft stands.

\section{THE ENVIRONMENTAL NOISE MONITORING \& ASSESSMENT STUDY}

The environmental management system in place sets up the framework for the achievement of relevant targets and leads

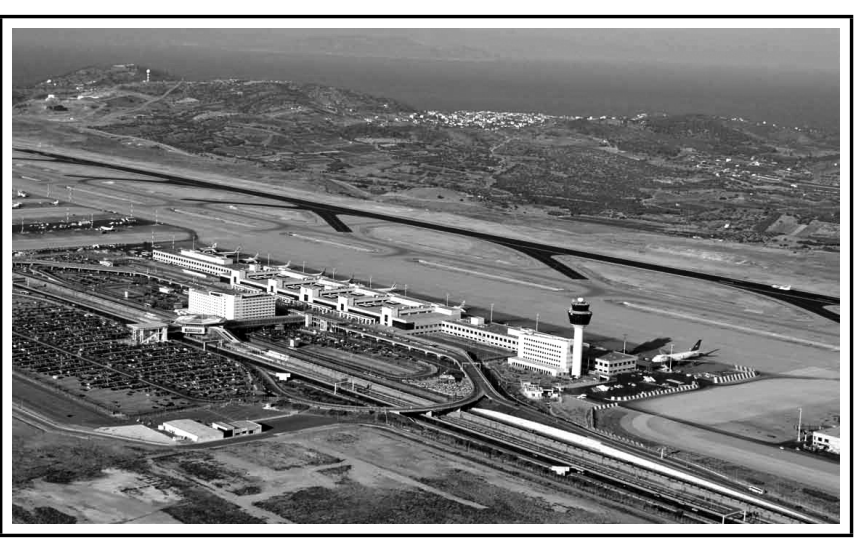

Figure 1. Athens International Airport (Source: Airliner World, February 2010).

to continuous improvements, ensuring compliance with environmental legislation and a strict policy. The airport noise is doubtless the greatest, though unfortunately unavoidable, environmental issue for the communities surrounding the airport. AIA strives to keep the impact as low as possible. Therefore, noise abatement procedures for the airport have already been established, since the beginning of its operation, in cooperation with Hellenic Civil Aviation Authority, including measures for runway use, night-movement restrictions, engine testing, etc. A NOise MOnitoring System (NOMOS) has been installed in the local municipalities for recording flight-noise emissions and flight paths. Comment and complaint management has been implemented through a special telephone line, the "We Listen" line, where citizens can express their complaints or enquiries regarding environmental noise issues. A complete study on aircraft noise, ${ }^{3}$ according to the European Directive 2002/49 ${ }^{4}$ and the local Joint Ministerial Decision 13586/724- 